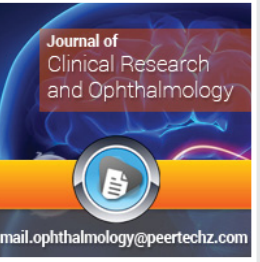

Clinical Group

\title{
Journal of Clinical Research and Ophthalmology
}

\section{Ivana Carevic ${ }^{1}$, Antonela Gverovic}

Antunica ${ }^{1 *}$, Helena Kastelan', Vedrana Iveta ${ }^{2}$, Sanja Zoranic ${ }^{3}$ and Snjezana Kastelan ${ }^{4}$

'Department of Ophthalmology and Optometry, General Hospital Dubrovnik, Dr. Roka Mišetića 2, 20000 Dubrovnik, Croatia

${ }^{2}$ Medical Centre Dubrovnik, Dr. Ante Starčevićeva 1, 20000 Dubrovnik, Croatia

${ }^{3}$ University of Dubrovnik UI. BraniteljaDubrovnika 29, 20000 Dubrovnik, Croatia

${ }^{4}$ Department of Ophthalmology, Clinical Hospital Dubrava, Avenija Gojka Šuška 6, 10000 Zagreb, Croatia

Received: 27 July, 2018

Accepted: 20 August, 2018

Published: 21 August, 2018

*Corresponding author: Antonela Gverović Antunica, Department of Ophthalmology and Optometry, General Hospital Dubrovnik, Dr. Roka Mišetića 2, 20000 Dubrovnik, Croatia, Email id: agantonela@net.hr

Keywords: Rhegmatogenous retinal detachment; Incidence; Dubrovnik neretva county; Vitrectomy; Retinal redetachment

https://www.peertechz.com

\section{Research Article}

\section{Epidemiolgy of Rhegmatogenous Retinal Detachment in Dubrovnik- Neretva County}

\section{Abstract}

Aim: This study is the first examination of the incidence of rhegmatogenous retinal detachment (RRD) in Dubrovnik- Neretva County, Croatia.

Method: Study is a retrospective and analyzed documentation from the Retinal clinic of the Ophthalmology and Optometry Department of the General Hospital Dubrovnik.

The annual incidence was calculated and analyzed in relation to sex, age, diagnosis year, affected eye, and visual acuity on diagnosis, visual acuity after therapy, type of therapy, localization of retinal detachment, risk factors, second eye rupture, redetachment, and presence of comorbidity.

Results: This study presents 92 examiners (94 eyes) who were in the period 1.1.2004 to 31.12.2013 diagnosed with the RRD. The youngest patient was 24 years old and the oldest 86 years. The largest number of cases was in the older age groups (61-70 years), at the age 60 to 80 there were 54 patients (57. $45 \%)$. The average age of all patients was 61.14 years.

The average annual number of patients was 9.4. Surgical procedure vitrectomy was performed for 82 (87.23\%) patients, $8(8.5 \%)$ had an operation with conventional ablation with cerclage and sealing, and 4 of them $(4.27 \%)$ did not undergo surgery, due to high level of retinal detachment or older age, comorbidity and high risk of general anesthesia.

Conclusion: The incidence of RRD in this study shows 7.65 on 100, 000 residents of DubrovnikNeretva County, and it is found to increase last years (2013 was 21 RRD) and in associations with myopia, cataract surgery and trauma.

\section{Introduction}

Retinal detachment is eye disorder in which the retina separates from the layer underneath $[1,2]$. There are 4 types of retinal detachment: rhegmatogenous, tractional, exudative, and solid retinal detachment. RRD is a result of a full-thickness defect of the sensory retina through which the diluted vitreous gel passes into the sub retinal space and drains the retina [3].

The first symptoms appear as lightning flashes, and if there is a rupture near the blood vessels and bleeding occurs, there are visible dark floating spots that decrease visual acuity depending on the amount of blood. The marked decline in visual acuity occurs when macula is affected [4].

Laser and freezing treatment procedures can repair a tear if it is diagnosed early enough. In pneumatic retinopexy the gas bubble is injected into the vitreous, while scleral buckle and vitrectomy are surgical procedures [5].

It is necessary to detect retinal detachment as soon as possible, because early onset therapy provides good success. In this study we analyzed ten years epidemiological status and treatment results in Dubrovnik- Neretva County.
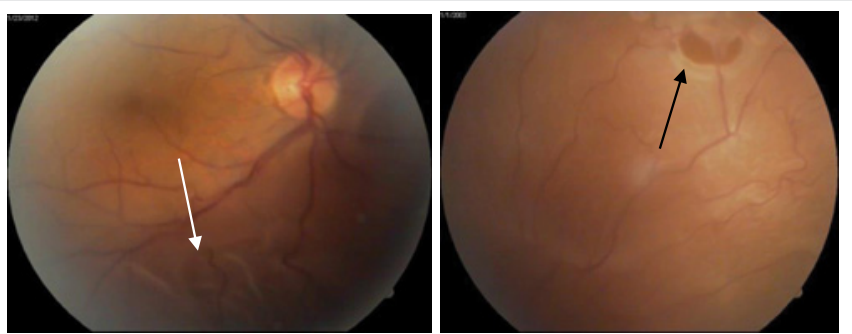

Picture 1: Black arrow shows rupture, white arrow shows retinal detachment (45year female patient). 


\section{Methods}

The study is retrospective, and from the archives of the Retinal Clinic of the Department of Ophthalmology and Optometry of the General Hospital of Dubrovnik patients with a diagnosis of rhegmatogenous retinal detachment in the period from 1.1.2004 to 31.12.2013 were analyzed. The study excluded patients which were not residents of Dubrovnik-Neretva County.

Dubrovnik- Neretva County is located in south Croatia, had 122568 residents, and $1781 \mathrm{~km}$ area. The county seat is Dubrovnik, and all patients with suspicion of retinal detachment are referred to the Retinal Clinic in Dubrovnik

All patients had complete ophthalmologic examination, including visual acuity with and without correction (Snellen charts, decimal), biomicroscopic examination of the anterior eye segment with pupil dilatation, measuring of intraocular pressure using a Goldman aplanation tonometer, examination with a Volk Trans Equator (Volk, Mentor, OH, USA) contact lens on the Haag Streit BQ 900 biomicroscope (Haag-Streit AG, Koeniz, Switzerland) and B scan (Ultrascan Imaging system Alcon)

From the Retinal Clinic archive following data was analyzed: sex, age, diagnosis year, affected eye, visual acuity on diagnosis, visual acuity after therapy, type of therapy, localization of retinal detachment, risk factors, second eye rupture, redetachment, and presence of comorbidity.

For data analysis descriptive and inferential statistics were used. Mean \pm standard deviation, and percentages were used as descriptive parameters of quantitative variables, and value of less than 0.05 was considered statistically significant. Differences in distributions of categorical data were evaluated by Chi-square test and comparison of means by $\mathrm{T}$ test. All statistical analyses were performed with the SPSS 13.0 software (SPSS Inc., Chicago, IL, USA).

\section{Results}

In this study there were 92 participants (94 eyes) involved which had rhegmatogenous retinal detachment diagnosed in a period from 1.1.2004 to 31.12.2013.

Number of patients per year is shown in the figure 1 and ranged from 3 patients in 2007 and 2008 to as many as 21 patients in 2013. The average annual number of patients was 9.4 which mean the incidence of rhegmatogenous retinal detachment in this study shows 7.65 on 100,000 residents of Dubrovnik-Neretva County.

Two patients had bilateral retinal detachment (2.12\%). There were 48 females $(51.1 \%)$ and $46(48.9 \%)$ males included in the study. There was no statistically significant difference in number $\mathrm{p}=0.835 \mathrm{p}>0.05$. The youngest patient was 24 years old and the oldest 86 years. The largest number of cases was in the older age groups. At the age 60 to 80 there were 54 patients $(57,45 \%)$. The mean age of all patients was 61.14 years.

The distribution by age group is shown in figure 2 .
In average, women were slightly younger than men (Table 1), but the difference in age between men and women was not statistically significant, $\mathrm{p}=0.197$.

The RRD in the left eye was in 51 patients $(56,38 \%)$ and in the right 43 patients. The difference in the number was not statistically significant, $\mathrm{p}=0.409$.

A surgical procedure for vitrectomy was performed for the largest number of $82(87.23 \%)$ patients, (79 preformed with silicon oil and 3 with gas tamponade) 8 patients (8.5\%) had an operation with conventional ablation with cerclage and sealing, and $4(4.27 \%)$ did not undergo surgery due to high degree of retinal detachment or older age and comorbidity and high risk of general anesthesia.

The study also analyzed the following risk factors for rhegmatogenous retinal detachment: cataract surgery before retinal detachment, myopia and eye trauma.

Forty-three (45.74\%) patients had no risk factor, 15 $(15.96 \%)$ had cataract surgery, 25 (26.59\%) had myopia and $9(9,57 \%)$ patients had trauma. Two patients had two risk factors simultaneously (Figure 3 ).

Comparison of the visual acuity values is shown in figure 4. Visual acuity after therapy improved in patients undergoing conventional retinal detachment and vitrectomy surgery. Visual acuity in patients which had not done the surgery was as expected worse.

Table 2 shows compared visual acuity before and after the treatment against risk factors. In all groups except those with a risk factor of trauma, visual acuity improved.

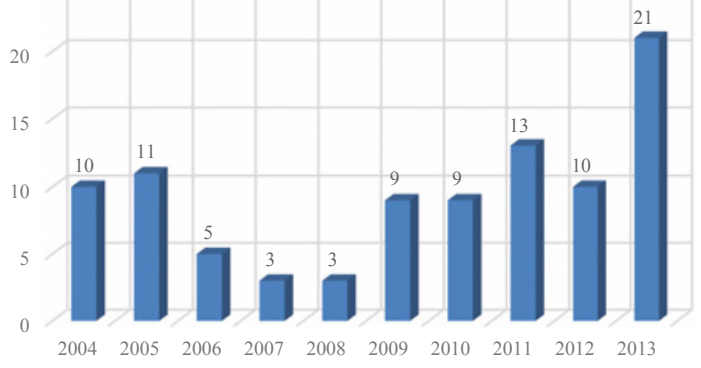

Figure 1: Number of patients per year.

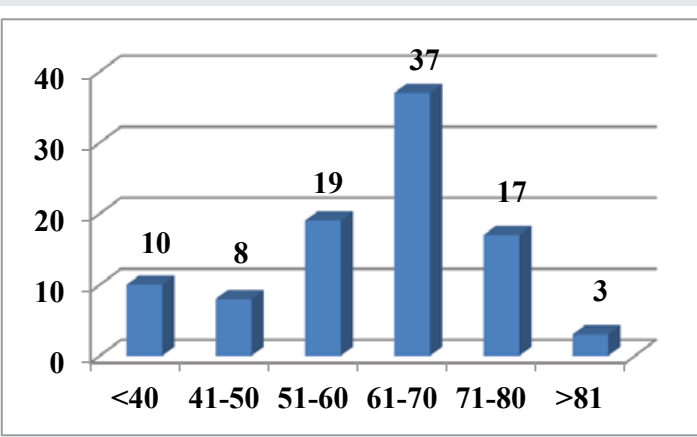

Figure 2: Distribution by age group 
Redetachment of the retina had $37(39.36 \%)$ of the total number of patients. The highest number - 13 (35.15\%) was in the group of myopia patients, 12 in the group without risk factors, and 6 in the group of cataract surgery and trauma (Figure 5).

The largest number of retinal redetachment in this study is at the age of $71-80$, and it was $13(25.1 \%), 10(27 \%)$ aged $61-70$ and 4 retinal redetachment under 40, 41- 50 and 51-60 years and at least $2(5,81-904 \%)$ at the age of 81-90.

The largest number of retinal redetachment in this study is at the age of $71-80$, and it was $13(25.1 \%), 10(27 \%)$ aged $61-70$ and 4 retinal redetachment under 40, 41- 50 and 51-60 years and at least $2(5,81-904 \%)$ at the age of 81-90.

Rupture in the second eye was found in 34 patients with retinal detachment: 16 myopic patients, 12 patients with no risk factor and 3 patients with cataract surgery and trauma (Figure 6).

The number of eyes with RRD recorded per season was 37 in spring, 19 in summer, 17 in winter, and 15 in autumn, and

Table 1: Mean age by gender.

\begin{tabular}{|c|c|c|}
\hline & Mean age \pm sd & Cl 95 \% \\
\hline Total & $61.14 \pm 13.16$ & $58.47-62.80$ \\
\hline Male & $62.32 \pm 13.21$ & $58.50-66.13$ \\
\hline Female & $60.00 \pm 13.16$ & $56.15-63.85$ \\
\hline
\end{tabular}

Table 2: Visual acuity before and after therapy depending on risk factor.

\begin{tabular}{|c|c|c|c|c|c|c|c|c|c|c|c|}
\hline \multirow{3}{*}{ Risk factor } & \multicolumn{10}{|c|}{ Visual acuity } & \multirow{3}{*}{$\begin{array}{c}\mathrm{X}^{2} \\
\mathrm{p}\end{array}$} \\
\hline & \multicolumn{5}{|c|}{ Before therapy } & \multicolumn{5}{|c|}{ After therapy } & \\
\hline & 0.1 & $\begin{array}{l}0.1- \\
0,3\end{array}$ & $\begin{array}{l}0.4- \\
0,6\end{array}$ & $\begin{array}{l}0,7- \\
0.9\end{array}$ & 1.0 & 0.1 & $\begin{array}{l}0.1- \\
0,3\end{array}$ & $\begin{array}{l}0.4- \\
0,6\end{array}$ & $\begin{array}{l}0,7- \\
0.9\end{array}$ & 1.0 & \\
\hline No risk factor & 36 & 6 & 3 & 0 & 0 & 27 & 7 & 4 & 5 & 2 & 0,07 \\
\hline $\begin{array}{l}\text { Cataract } \\
\text { surgery }\end{array}$ & 10 & 5 & 0 & 0 & 0 & 12 & 2 & 0 & 1 & 0 & 0,29 \\
\hline Myopia & 21 & 4 & 0 & 0 & 0 & 19 & 4 & 1 & 1 & 0 & 0,55 \\
\hline Trauma & 8 & 1 & 0 & 0 & 0 & 9 & 0 & 0 & 0 & 0 & 0,30 \\
\hline Total & 75 & 16 & 3 & 0 & 0 & 67 & 13 & 5 & 7 & 2 & 0,04 \\
\hline
\end{tabular}

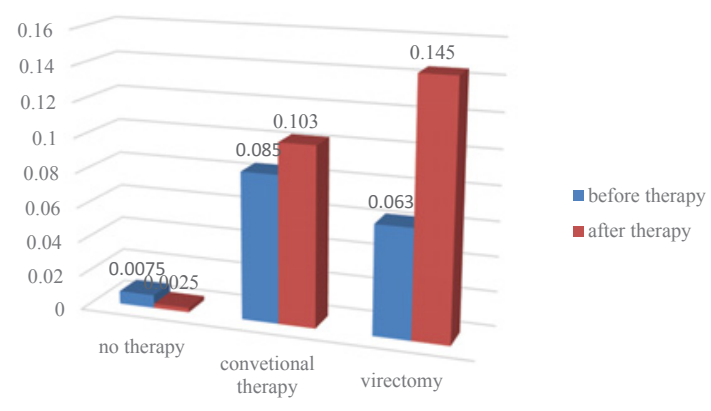

Figure 4: Visual acuity before and after therapy depending on therapy.

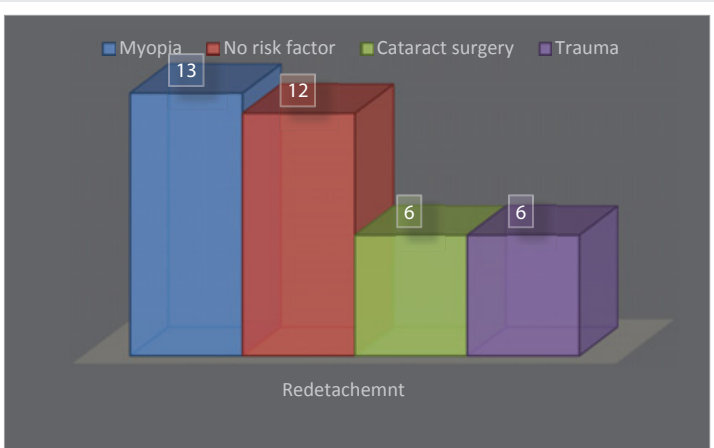

Figure 5: Number of retinal redetachment depending on risk factors.

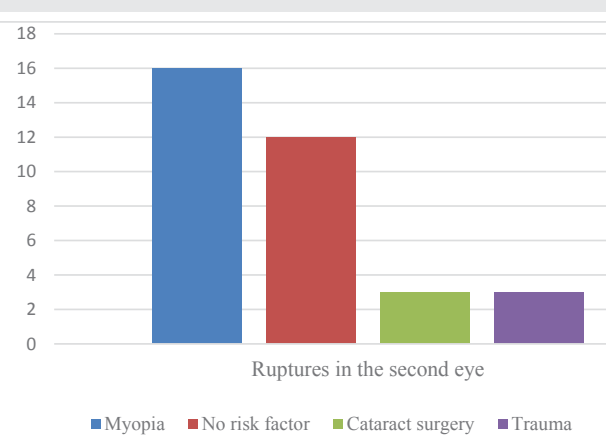

Figure 6: Number of ruptures in the second eye depending on risk factors.

that is statistically significant difference according to seasons $\mathrm{p}=0.029$. On average in Dubrovnik July is the sunniest month. In most of studies light is suggested as a precipitating factor for RRD in a damaged retina, but in our study the most cases of RRD were in spring, and we have not explanation for that.

Of 94 eyes with RRD $68 / 72 \%$ ) had retinal tear in upper quadrants, and macula off had $78(83 \%)$ patients?

\section{Discussion}

Incidence of rhegmatogenous retinal detachment in this study shows 7.65 on 100,000 residents of Dubrovnik-Neretva County. Through observed decade there were significant differences of incidence from 2, 4 on 100,000 residents in 2007 and 2008 to as many as 17.21 on 100,000 residents in 2013. The exact reason is unknown, but the potential cause might be a greater number of ultrasound treatments of cataracts. 
In Croatia there is only one study about RRD. Ivanišević et al. analyzed population of Split- Dalmatia County, Croatia and during 11-year period found the annual incidence is 5.4 per 100,000 residents, but in this study authors presented nontraumatic phakic rhegmatogenous retinal detachment [6].

Literature states that European countries have between 6, 9 to 18, 2 incidences of RRD on 100, 000.00 residents: Laatikainen in Helsinki [6,7,9] Törnquist et al. [8] 10.6 and Algvere [9] 14 in Sweden, Mitry [10] in Scotland 12.05, and Van de Put MA 18.2 in Netherland [11]. These studies have different inclusion criteria and analyzed time, so the comparison does not have to be valid.

Li states yearly incidence of 7.98 on 100,000 residents of Beijing China [12].

In our study no statistically significant difference by sex was found, while the most studies showed a greater incidence in male population $[6,13-17]$.

The higher incidence in women was found in a small number of studies in the pseudophakes and in the non-traumatic group [18-22].

In most studies the right eye is often more affected by the ratio R:L 1.09:1 and 1.36:1. [7,12,18,19], but in this study the difference was not statistically significant.

The most risk factor in our study was myopia, similar as found in most studies $(8,10)$. Other commonly mentioned risk factors are cataract surgery or eye or head trauma $[7,12,15]$.

In this study $2.12 \%$ had bilateral RRD, less than Tomquist study $11.2 \%$ (8) and Benmerzouga $4.11 \%$ in the general population, and in high myopia patients $9.17 \%$ [23]. From the documentation it is evident that our patients with bilateral RRD did not perform regular ophthalmological control exam.

Retinal redetachment in our study is too high as $39.36 \%$ of the total number of patients. Goezinne reported a significantly lower redetachment rate of $7 \%$, but only those who developed retinal redetachment 6 months after the conventional ablation surgery were included in the study [21].

Li stated in his work that after 310 days of observation, 11 out of 105 eyes (10.4\%) developed redetachment after removal of silicone oil. There was a significant difference in aphakia eyes $21.1 \%$ and phakia or pseudo-phakia $4.5 \%$ [22].

The possible reasons for such a high percentage of redetachment in our patients are a late arrival to a medical examination at Retinal Clinic, long waiting lists for a surgery treatment and a distance from the centers where the vitectomy is performed. There are only a few centers in Croatia where vitrectomy can be performed. By 2013, all our patients were referred to Zagreb which is $600 \mathrm{~km}$ away from Dubrovnik. All the aforementioned reasons have encouraged the education of ophtalmologists for Pars plana vitrectomy surgery and the procurement of equipment which is being underway. We do hope that the quicker surgery will result in the better postoperative outcomes.

\section{Author Contributions}

The case report was written by all authors. All authors read and approved the final manuscript.

\section{References}

1. Cerovski B (2012) OFTALMOLOGY - Textbook for medical students Link: https://tinyurl.com/y9ufqrr5

2. Busic M, Kuzmanovi Elabjer B, Bosnar D (2014) Ophthalmologic Seminar (Ophthalmology and Optometry Tutorial) 3. Issue Osijek. Link: https://tinyurl.com/y7d6fvq9

3. Ghazi N G, Green WR (2002) Pathology and pathogenesis of retinal detachment. Eye (Lond) 16: 411-21. Link: https://tinyurl.com/yajuukzc

4. Kuzmanovic Elabjer B, Busic M, Bosnar D (2013) Atlas ultrasound - ultrasonic view of pathological eye conditions and orbits. Link: https://tinyurl.com/ydhwevs4

5. (1993) The Eye Disease Case-Control Study Group “Risk factors for idiopathic rhegmatogenous retinal detachment. American Journal of Epidemiology 13 749-757. Link: https://tinyurl.com/y6w5ctz5

6. Ivanisevic M, Bojic L, Eterovic D (2000) Epidemiological study of nontraumatic pseudophakic rhegmatogenous retinal detachment Ophth Res 32: 237-923. Link: https://tinyurl.com/ybp3m7dq

7. Laatikainen L, Tolppanen EM, Harju H (1985) Epidemiology of rhegmatogenous retinal detachment in a Finish population Acta Opthalmol 63: 59-64. Link: https://tinyurl.com/y8fzcs9h

8. Tornquist R, Stenkula S, Tornquist $P$ (1887) Retinal detachment. A study of a population-based patient material in Sweden 1971-1981. I. Epid Acta Ophthalmol 65: 213-222. Link: https://tinyurl.com/y99koosp

9. Algvere PV, Jahnberg P, Textorius O (1999) Graefes Arch Clin Exp Opthalmol 237: 137-144

10. Mitry D, Charteris DG, Yorston D, Siddiqui MA, Campbell H, et al. (2010) Scottish RD Study Group Invest Ophthalmol Vis Sci 51: 4963-4968. Link: https://tinyurl.com/ycvutuof

11. Van de Put MAJ, Hooymans JMM, Los LI (2013) The incidence of rhegmatogenous retinal detachment in The Netherlands. Ophthalmology 120: 616-622. Link: https://tinyurl.com/yajpgtua

12. Li X (2003) Incidence and epidemiological characteristics of rhegmatogenous retinal detachment Beijing, China. Ophthalmology 110: 2413-2417. Link: https://tinyurl.com/y9eos2ka

13. Limeira-Soares PH, Lira RP, Arieta CE, Kara-Jose N (2007) Demand incidence of retinal detachment Brazil. Eye 21: 348-352. Link: https://tinyurl.com/y6wepu4s

14. Mowatt L, Shun-Shin G, Price N (2003) Ethnic differences in the demand incidence of retinal detachment in two districts in the West Midlands Eye 17: 63-70. Link: https://tinyurl.com/yct3db7x

15. Mitry D, Charteris DG, Fleck BW, Campbell H, Singh J (2010) The epidemiology of rhegmatogenous retinal detachment: geographic variation and clinical associations. $\mathrm{Br} \mathrm{J}$ Ophthalmol 94: 678-684. Link: https://tinyurl.com/yamnau84

16. Rosman M, Wong TY, Ong SG, Ang CL (2001) Retinal detachment in Chinese Malay and Indian residents in Singapore a comparative study on risk factors, clinical presentation and surgical outcomes. Int Ophthalmol 24: 101-106. Link: https://tinyurl.com/y819nw68

17. Sasaki K, Ideta H, Yonemoto J, Tanaka S, Hirose A, et al. (1995) Epidemiologic characteristics of rhegmatogenous retinal detachment in Kumamoto Japan Gaefes Arch Exp Ophhtalmol 233: 772-776. Link: https://tinyurl.com/yc74r5jy 
18. Haimann MH, Burton TC, Brown CK (1982) Epidemiology of retinal detachment Arch Ophthalmol 100: 289-292. Link: https://tinyurl.com/y9t2xzls

19. Rowe JA, Erie JC, Baratz KH (1999) Retinal detachment in Olmsted County, Minnesota, 1976 through 1995. Ohthalm 106: 154-159. Link: https://tinyurl.com/y9yqj299

20. Austin KL, Palmer JR, Seddon JM, Glynn RJ, Rosenberg L, et al. (1990) Casecontrol study of idiopathic retinal detachment. Int J Epidemiol 19: 10451050. Link: https://tinyurl.com/y6wuuowh
21. Goezinne F, La Hei EC, Berendschot TT, Keesels AG, Liem A, et al. (2010) Incidence of redetachment 6 month after sclera buckling surgery. Acta Ophthalmol 88: 199-206. Link: https://tinyurl.com/y8pw7sdq

22. Li H, Zhu X, Jiang D (2005) Risk factors of retinal redetachment after expected silicone oil removal. Yan KeXu Bao 21: 92-94. Link: https://tinyurl.com/ybasknpm

23. Benmerzouga Mahfoudi N, Chaker Harbi M, Boulaneb Beddiar F, Chachoua (2015) Bilateral retinal detachment and high myopia: report of nine cases J Fr Ophtalmol 38: 141-145. Link: https://tinyurl.com/y9mfoxw5

Copyright: @ 2018 Carevic I, et al. This is an open-access article distributed under the terms of the Creative Commons Attribution License, which permits unrestricted use, distribution, and reproduction in any medium, provided the original author and source are credited. 